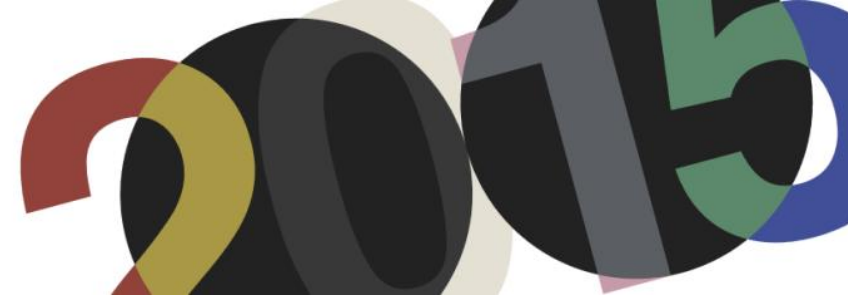

DOI: http://dx.doi.org/10.4995/LC2015.2015.713

\title{
Le Corbusier y la Reorganización del hábitat rural
}

\author{
D. Arredondo Garrido
}

Escuela Técnica Superior de Arquitectura de Granada

\begin{abstract}
Resumen: El conjunto de proyectos de reorganización del hábitat rural desarrollados por Le Corbusier en la década de los treinta supusieron una nueva mirada sobre un sector de la sociedad que aún no se había sumado a la modernidad. A través de la Ferme Radieuse y el Village Radieux, combinados en la Unité d'explotation agricole, Le Corbusier elaboró una teoría de desarrollo territorial que incorporaba la tecnología, mejoraba la habitabilidad y aumentaba la inclusión social de los agricultores, sin perder la esencia del contacto con la naturaleza. Planteó un modelo de reforma agraria basado en el mantenimiento de la propiedad y la constitución de cooperativas de propietarios-trabajadores agrícolas, organizado por medio de una exhaustiva conectividad entre funciones y materializado gracias al uso de técnicas y sistemas constructivos contemporáneos. Una reorganización que entendemos merece una relectura contemporánea, que profundice en estos proyectos gestados desde la modernidad más avanzada, con una mirada universal buscando el desarrollo completo de un "homme réel" conectado con el territorio.
\end{abstract}

Abstract: Le Corbusier's rural reorganization developed in the thirties compromised a new approach to a sector of the society that had not yet joined modernity. Through the Ferme Radieuse and the Village Radieux, combined in the Unité d'explotation agricole, Le Corbusier designed a theory of territorial development that included technology, improved habitability and increased social inclusion of farmers, without losing the essence of contact with nature. He created a model of agrarian reform based on the maintenance of the property and the establishment of land owner-workers cooperatives. It was organized by a comprehensive connectivity between functions and materialized through the use of contemporary techniques and building systems. A reorganization that deserves a contemporary reinterpretation to deepen in these projects, which were created from the most advanced modernity, with a universal point of view, seeking for a full development of a "homme reel" connected to the land.

Palabras clave: Reorganización rural; años 30; Ferme Radieuse; Village Radieux; Unité d'explotation agricole. Keywords: Rural reorganization; thirties; Ferme Radieuse; Village Radieux; Unité d'explotation agricole.

\section{Introducción}

Durante el primer tercio del siglo XX se desarrollaron un conjunto de proyectos que propusieron una reconciliación entre los impulsos de las metrópolis industriales y las condiciones sociales, culturales y naturales de los asentamientos agrícolas, aspirando a conseguir un "urbanismo agrario". Como la mayoría de los proyectos de utopías urbanas $^{2}$, no concluyeron en objetos construidos, aunque podemos estudiarlos gracias a sus espléndidas representaciones. En ellas son presentados como asentamientos ideales, exentos de los problemas de las grandes metrópolis de la primera mitad del siglo XX. Sin embargo, no deben verse únicamente como ensoñaciones, sino que se constituyen en interesantísimas críticas a la sociedad del momento, respondiendo a sus

\footnotetext{
1 Waldheim, Charles: "Notes Toward a History of Agrarian Urbanism" en Bracket 1: On Farming, White, Mason; Przybylski, Maya (Eds.). Barcelona: Actar, 2010. pp. 18-24.

${ }^{2}$ Este tema ha sido ampliamente estudiado en la tesis doctoral, David Arredondo Garrido: Agricultura en la ciudad. De la utopía a la conciencia de lugar. Directores: Juan Calatrava y Juan Manuel Barrios. Universidad de Granada, 2013.
} 
problemas sociales, económicos o medioambientales. Se sitúan, por tanto, en plena consonancia con las corrientes de renovación arquitectónica que constituyeron el Movimiento Moderno.

Como ejemplos más relevantes podríamos destacar la propuesta de ciudades disueltas en la naturaleza que hizo Bruno Taut $^{3}$ tras la Primera Guerra Mundial; la ciudad lineal propuesta por Moise Ginzburg ${ }^{4}$ a finales de los 20; el desarrollo de una ciudad dispersa hasta el infinito en las praderas americanas de Frank Lloyd Wright ${ }^{5}$; la organización de un plan agrícola territorial que planteó Ludwig Hillberseimer ${ }^{6}$; y finalmente, la Reorganización Rural que diseñó Le Corbusier entre la década de los 30 y comienzos de los 40.

El enfoque de estas propuestas de "urbanismo agrario" fue esencialmente funcionalista, entendiendo que la correcta distribución de las actividades humanas en el territorio permitiría una mejora de la sociedad. En ellas lo agrario estaba claramente presente, siendo, más que uno de los ejes sobre los que se apoyaba su diseño, el elemento estructurante de las sociedades ideadas.

\section{Objetivos}

Este artículo pretende un conocimiento más profundo de los citados proyectos de Le Corbusier. Entendemos que merecen una relectura contemporánea, en un momento en el que se están considerando nuevos modos de interacción entre lo urbano y lo rural. Son numerosos los proyectos actuales que pretenden diseñar una conexión más sana y justa entre la vida en las ciudades y los valores naturales, culturales y alimentarios de lo agrario. Una mirada que, incluyendo lo paisajístico y medioambiental, añade la perspectiva de la seguridad alimentaria y la cohesión social de los territorios.

Los proyectos de reorganización del hábitat rural diseñados por Le Corbusier incluían ya un análisis complejo de esta situación, poniendo en conexión directa la funcionalidad de estos territorios, su valor cultural y paisajístico, así como su interrelación con el resto de sectores de la vida contemporánea. Así, se han estudiado los proyectos originales publicados por el propio autor, documentación del archivo de su fundación, revisiones y reediciones de estas obras, así como las investigaciones más relevantes sobre este conjunto de proyectos. Este artículo irá analizando las diferentes fases del desarrollo mediante un relato cronológico para llegar a un mejor entendimiento de sus influencias, conexiones e intenciones, y avanzar en el conocimiento de estos proyectos.

\section{Contexto}

El conjunto de proyectos formado por la Ferme radieuse ${ }^{7}$, el Village radieux ${ }^{8}$ y la posterior implementación de ambos como Unité d'explotation agricole en la teoría urbanística de Les Trois Établissements Humains ${ }^{9}$, puede

\footnotetext{
${ }^{3}$ Taut, Bruno: Die Auflösung der Städte. Die Erde eine gute Wohnung, der Weg zur alpinen Architektur. Hagen: Folkwang, 1920. Recogido en castellano en: Taut, Bruno: Escritos, 1919-1920, Iñaki Ábalos (Ed.). Madrid: Croquis, 1997.

${ }^{4}$ Ginzburg, Moisei; Barshch, Mikhail: "Zelenyj Gorod”. SA Sovremennaya Arkhitektura. 1930, № 1-2. p. 22.

${ }^{5}$ Este proyecto se encuentra en diferentes fases de desarrollo en: Wright, Frank Lloyd: The Disappearing City. New York: W. F. Payson, 1932; Wright, Frank Lloyd: When Democracy Builds. Chicago: University of Chicago Press, 1945; y Wright, Frank Lloyd: The Living City. New York: Horizon Press, 1958.

${ }^{6}$ Hilberseimer, Ludwig: The New Regional Pattern: Industries and Gardens, Workshops and Farms. Chicago: P. Theobald, 1949.

${ }^{7}$ El proyecto de Ferme Radieuse se desarrolló entre 1933 y 1934. Archivo en Fondation Le Corbusier (FLC) H3-16 y L3-20.

${ }^{8}$ El proyecto del Village Radieux se desarrolló entre 1934 y 1937, ver: FLC H3-16 y L3-20.

${ }^{9}$ Edición original, Le Corbusier: Les Trois Établissements Humains. Paris: Éditions Denoël, Collection ASCORAL, 1945; posteriormente en Le Corbusier: L’urbanisme des trois établissements humains. Paris: Ed. de Minuit, 1959. Versión en
} 
entenderse como una auténtica propuesta de reorganización del hábitat rural. Este conjunto de ideas estuvieron presentes en el pensamiento de Le Corbusier desde mediados del año 1933 hasta sus últimos días. Así quedó reflejado en su obra testimonio, Mise au Point ${ }^{10}$, en donde dedicó una parte importante del texto a recordar y reformular este modelo de organización territorial, ampliamente cribado a lo largo de tres décadas.

El desarrollo de estos proyectos se llevó a cabo en una década, los años 30 del siglo XX, en donde la habitual y probablemente ya superada, división bipartita de la obra de Le Corbusier dificulta su catalogación. Durante estos años, pese a mantener una actitud cercana al determinismo tecnológico, su interés por el lugar y la concepción orgánica o bilógica de los proyectos estaba ya patente. En un período no muy amplio de tiempo se sucedieron manifestaciones que demuestran una evolución en su pensamiento que también afecta a su relación con el mundo rural, objeto de esta investigación. De manera que en los textos del proyecto de 1925 de Ville Contemporaine pour Trois Millions d'Habitants, Le Corbusier calificaba las actividades de jardinería y horticultura en las viviendas para obreros a las afueras de la ciudad como "ejercicio sano (..) algo estúpido, inefectivo y a veces peligroso $^{\prime 11}$. Y en 1931, en la revista Plans, y sobre la foto aérea de una superficie agrícola de la Alsacia altamente subdividida en parcelas, declaraba que "vivimos en la era de la máquina pero las máquinas no puede ser usadas aquí"12.

Sin embargo a partir de 1933, en paralelo al reconocimiento de las singularidades territoriales, geográficas y culturales que demostró tras sus viajes y proyectos en Sudamérica y el norte de África, Le Corbusier estaba estableciendo un orden orgánico en su arquitectura. Un orden nuevo (ordre nouveau) que se conseguiría por medio de la defensa del medio natural así como de los derechos biológicos universales del hombre real (homme réel), como escribió en la Ville Radieuse:

“ (...) el sol en el alojamiento, el cielo a través de los cristales de la vivienda, los árboles bajo los ojos (...) tocan lo más profundo del ser fisiológico y del ser psicológico. Nos ponen en armonía con nuestro profundo destino natural",13.

Y en 1934 incluiría ya la siguiente reflexión en sus CEuvre Complète:

"No es posible pensar en urbanizar las ciudades modernas si no pensamos en desarrollar el campo. Algunos de los habitantes de la ciudad volverán al campo. Pero si éste sigue siendo lo que es hoy, nadie querrá volver. Para ello es necesaria la reordenación del suelo, la construcción de poblados de cooperación y establecer un nuevo tipo de granja, utilizando la maquinaria de la cultura moderna"l4.

Mary Mcleod ${ }^{15}$ defiende que, en paralelo a esta evolución, la mayor influencia de su interés por lo agrario se debió al contacto con el sindicalismo regional. Un movimiento político de amplio espectro en el que Le

castellano Le Corbusier: El Urbanismo de los Tres Establecimientos Humanos, Junyent, Albert (Tr.). Barcelona: Poseidón, 1981.

${ }^{10}$ Edición facsímil en castellano de la obra original de 1966, Le Corbusier: Mise au point. Torres Cueco, Jorge (Ed.). Madrid: Abada Editores, 2014. Incluye el ensayo, Torres Cueco, Jorge: Pensar la Arquitectura: 'Mise au point' de Le Corbusier. Madrid: Abada Editores, 2014.

${ }^{11}$ Le Corbusier: The City of To-Morrow and Its Planning (1925). New York: Dover, 1987. pp. 202-03. Citado por McLeod, Mary: "Le Ferme Radieuse. Le Village Radieux," en Le Corbusier et La Nature. Paris: Fondation Le Corbusier - Editions de la Villette, 2004. p. 130. (Traducción desde el inglés por autor).

${ }^{12}$ Le Corbusier: "Décisions". Plans, Diciembre 1931, № 10. (Traducción desde el frances por autor).

${ }^{13}$ Citado en Torres Cueco, Jorge: Pensar la Arquitectura (...). op. cit. pp. 105-6. Original en Le Corbusier: La Ville Radieuse. Boulogne-sur-Seine: Editions d'Architecture d'Aujourd'hui, 1935. p. 14 y p. 43.

${ }^{14}$ Le Corbusier: Euvre Complète 1929-1934. Zurich: Girsberger, 1935. p. 186. (Traducción desde el francés por autor).

${ }^{15}$ McLeod, Mary: "Urbanism and Utopia: Le Corbusier from Regional Syndicalism to Vichy”. Princeton University, 1985. 
Corbusier participó como editor y autor de artículos en varias de sus revistas. En las páginas de Plans (1931-32), Prèlude (1933-36) y L'Homme Rèel (1934) aparecieron artículos en los que el grupo propugnaba una descentralización tecnicista del gobierno. Jeanne Walter, Philippe Lamour, Hubert Lagardelle participaban, junto a Le Corbusier y otros, en estas publicaciones que ansiaban una planificación social dirigida por tecnócratas ${ }^{16}$. Frente a la improductividad e incapacidad de las instituciones democráticas, preferían una autoridad que procediera de la capacitación técnica ${ }^{17}$, una acción directa frente al capitalismo por medio de la intervención económica y la descentralización progresiva del gobierno ${ }^{18}$.

La intención final era el desarrollo completo del ser humano en una sociedad orgánica. Para ello, uno de los puntos destacados en sus propuestas políticas fue la reforma agraria. Reforma que debía producirse por la aplicación científica de las innovaciones técnicas y sociales. Y que entendía el trabajo en un sentido antropológico, como un intercambio con la naturaleza, un control del hombre sobre el medio ${ }^{19}$.

En el seno de este grupo se produjo el encuentro con el agricultor y activista sindical Norbert Bézard. Por intermediación del Doctor Peter Winter y de Philippe Lamour ${ }^{20}$, Bézard comenzó una correspondencia con Le Corbusier que sería el germen de sus proyectos rurales. En su carta de 1933, que el propio arquitecto suizo reprodujo en el capítulo 7 de La Ville Radieuse ${ }^{21}$, Bézard le pedía:

"Le Corbusier, ino te quedes en la ciudad; ¿Piensas que nosotros leemos con ojos indiferentes las descripciones de vuestra Ciudad Radiante? ¿Quieres ocuparte un poco de nosotros, acordarte de nuestras campiñas, nuestras granjas, nuestros campos, nuestros pueblos (...) Corbusier [sic], danos la Granja Radiante, el Pueblo Radiante $^{, 22}$.

Durante el año 1933 Bézard introdujo a Le Corbusier en el mundo rural a través de "una larga, paciente y meticulosa asimilación" $"$. A lo largo de sus visitas a la campiña de la región de Sarthe, en el noroeste de Francia, y de sus reuniones con los agricultores ${ }^{24}$, Le Corbusier apreció una general mala organización y un atraso en las viviendas e infraestructuras de los agricultores. Este nuevo interés le animó a la lectura de geógrafos e historiadores rurales como L' Histoire de la Campagne Française de Gaston Ruopnel, La Terre au Paysan de Henri Pitaud y Questions de Charles Ferdinad Ramuz ${ }^{25}$. Así, en el futuro trabajo sobre Les Trois Établissement Humains, recogería unas frase de Gaston Roupnel abogando por la bondad del trabajo cooperativo en el campo: "Los pueblos deberán transformarse en una asociación de trabajadores y en una cooperativa de producción.

\footnotetext{
${ }^{16}$ Ragot, Gilles: "La Ferme et le Village Radieux de Le Corbusier. Nouvelle déclinaison du principe d'équilibre entre l'individuel et le collectif'. In Situ. Revue des patrimoines, julio 2013, No 21.

${ }^{17}$ Lourau, René: El Estado y el inconsciente: ensayo de sociología política. Barcelona: Kairós, 1980. p. 164.

${ }^{18}$ Ragot, Gilles: "La Ferme et le Village radieux de Le Corbusier (...)”. op. cit.

${ }^{19}$ Thilo Hilpert, “La Maison des Hommes: Leçons Possibles de L'anthropocentrisme de Le Corbusier," en Le Corbusier et la Nature. Paris: Fondation Le Corbusier - Editions de la Villette, 2004. p. 23.

${ }^{20}$ Ragot, Gilles: "La Ferme et le Village radieux de Le Corbusier (...)". op. cit.

${ }^{21}$ Le Corbusier: "Réorganisation Rurale," en La Ville Radieuse. Paris: Vincent Fréal and Cie., 1964. pp. 319-36. Y antes de ello en Prèlude. 1934, No 4.

${ }^{22}$ Ibíd., 321. (Traducción desde el francés por autor).

${ }^{23}$ Ibíd., 324.

${ }^{24}$ Por ejemplo la que llevó a cabo con 50 agricultores en la ciudad de Le Mans, ver: Mary McLeod, "Piacé: Ferme Radieuse and Village Radieux," en Le Corbusier: An Atlas of Modern Landscapes, Cohen, Jean-Louis (Ed.). New York: Museum of Modern Art, 2013. p. 188.

${ }^{25}$ McLeod, Mary: "Le Ferme Radieuse. Le Village Radieux". op. cit. p. 136.
} 
Volverán los tiempos de la explotación colectiva; volverán los tiempos originales en los que cada uno estaba al servicio de todos ${ }^{, 26}$.

El conocimiento de primera mano, tanto práctico como teórico, de la situación de la región hizo que Le Corbusier se cuestionara cómo exportar las ideas del planeamiento racionalista al mundo rural. Pese a que en esos años se estaban imponiendo proyectos de reforma agraria de explotación extensiva, a gran escala y de gestión gubernamental ${ }^{27}$, la idea de Le Corbusier era la modernización de las producciones agrícolas familiares, la mejora de su competitividad y de las condiciones sociales de sus habitantes sin perder los valores naturales. Por ello sus propuestas no exigen la disolución de la propiedad privada, ni la gestión gubernamental, sino que parten de un cooperativismo ${ }^{28}$ cercano al añorado por Roupnel, en donde la propiedad permanece en el campesinado y las cooperativas tienen un peso importante en la gestión.

\section{Ferme Radieuse}

La organización rural propuesta por Le Corbusier partía de la reordenación de un trabajo familiar cooperativo en las granjas. Por lo tanto, el primero de los proyectos a desarrollar debía ser el de un nuevo modelo de granja: la Ferme Radieuse. Éste apareció por primera vez en el número 14 de la revista Prèlude en noviembre de $1934^{29}$. Poco después se publicó en el número 4 de la revista L'Homme Réel ${ }^{30}$ y luego dentro de la Ville Radieuse ${ }^{31}$.

Se trata de una explotación agrícola de $20 \mathrm{Ha}$ gestionadas por una sola familia. Consta de una vivienda y una serie de construcciones que albergan los usos necesarios para la explotación agrícola y ganadera de la propiedad. El tamaño y la estructura fue el resultado de la adaptación del proyecto a la zona de Piacé, de donde procedía Bézard, que sirvió de emplazamiento teórico de la propuesta. Esta influencia se aprecia fundamentalmente en la elección de un tamaño de explotación medio, que correspondía a un territorio de bocage ${ }^{32}$, como se denomina en la región a la zona con suaves pendientes, subdividida en parcelas, en donde se alternan pastos y bosques. Pese al emplazamiento elegido, el modelo es claramente teórico y según el propio autor, debería adaptarse a los diferentes regímenes climáticos y condiciones topográficas.

Le Corbusier entendió desde el inicio la granja como “(...) una biología, un organismo, un ser. (...) Incorpora la tierra, el territorio, la naturaleza y el trabajo humano. ¡Está viva!”33. Este organismo tendría las mismas partes que el ser humano: “órganos de decisión, de locomoción, de manipulación y de almacenamiento"34. De manera que una vía central permite la ordenación interna de las diversas construcciones funcionales de la granja y su conexión con los pastos.

\footnotetext{
${ }^{26}$ Le Corbusier: Les Trois Établissements Humains. op. cit. pp. 77-78. (Traducción desde el francés por autor).

${ }^{27}$ Por ejemplo en la URSS. Ver más en McLeod, Mary: "Radiant Farm and Village: Le Corbusier's Agricultural Utopia, 1933-1942". Dumbarton Oaks, Washington: D. O. Garden and Landscape Studies. 2012.

${ }^{28}$ McLeod, Mary: "Piacé: Ferme Radieuse and Village Radieux". op. cit. p. 187.

${ }^{29}$ Le Corbusier: "Ferme Radieuse, Village Radieux". Prélude. op. cit.

${ }^{30}$ Le Corbusier: "Village Radieux, Ferme Radieuse". L’Homme Réel. 1934, № 4. pp. 54-59.

${ }^{31}$ Le Corbusier: "Réorganisation Rurale". op. cit.

${ }^{32}$ Así define Bézard el territorio de Piacé a Le Corbusier en la carta recogida en Ibíd., p. 322. y en el dibujo incluido en incluido en En Bézard, Norbert: "Rapport: L’Urbanisme Rural”, En 5 Congrés de Paris 'Logis et Loisirs'. Boulogne-surSeine: Editions d'Architecture d'Aujourd'hui, 1938. p. 15.

${ }^{33}$ Le Corbusier: "Réorganisation Rurale". op. cit. p. 325. (Traducción desde el francés por autor).

${ }^{34}$ Le Corbusier: La Ville Radieuse. op. cit. p. 82. Cita recogida en castellano por García-Germán, Javier: "De la Ville Verte a la Geoarquitertura," Massilia. Annuaire d'Etudes Corbuseennes. 2008, № 7. p. 197.
} 
La vivienda se emplaza separada del espacio de trabajo, en una edificación independiente en el corazón de la explotación. Su posición central y elevada sobre pilotis, permite el control visual de las cosechas extensivas para alimento de los animales, del huerto de frutales, de la granja de aves y de los establos en el patio de trabajo. El uso de pilotis permite evitar la humedad en la vivienda ${ }^{35} \mathrm{y}$ facilita el contacto directo desde la planta baja abierta hacia el jardín de recreo y el huerto de vegetales junto a la residencia. La planta alta se organiza a partir de una gran sala que alberga la cocina y el salón, completada por tres dormitorios y dos baños. La construcción se haría con elementos prefabricados sobre una estructura metálica, consiguiendo grandes ventanales, cerramiento de paneles y cubierta plana recubierta de tierra.

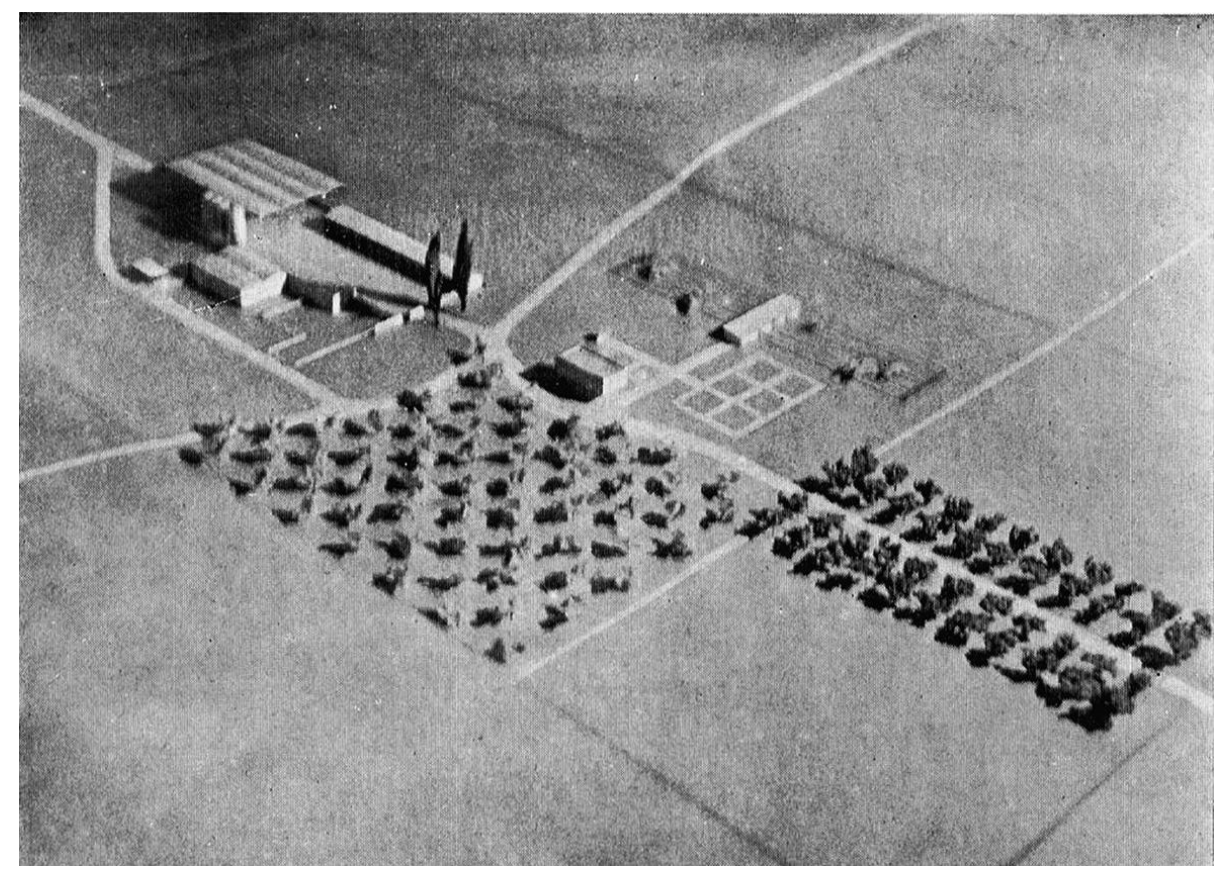

1. Maqueta de la Ferme Radieuse publicada en Le Corbusier: Euvre Complète 1929-1934. Zurich: Girsberger, 1935. p. 188.
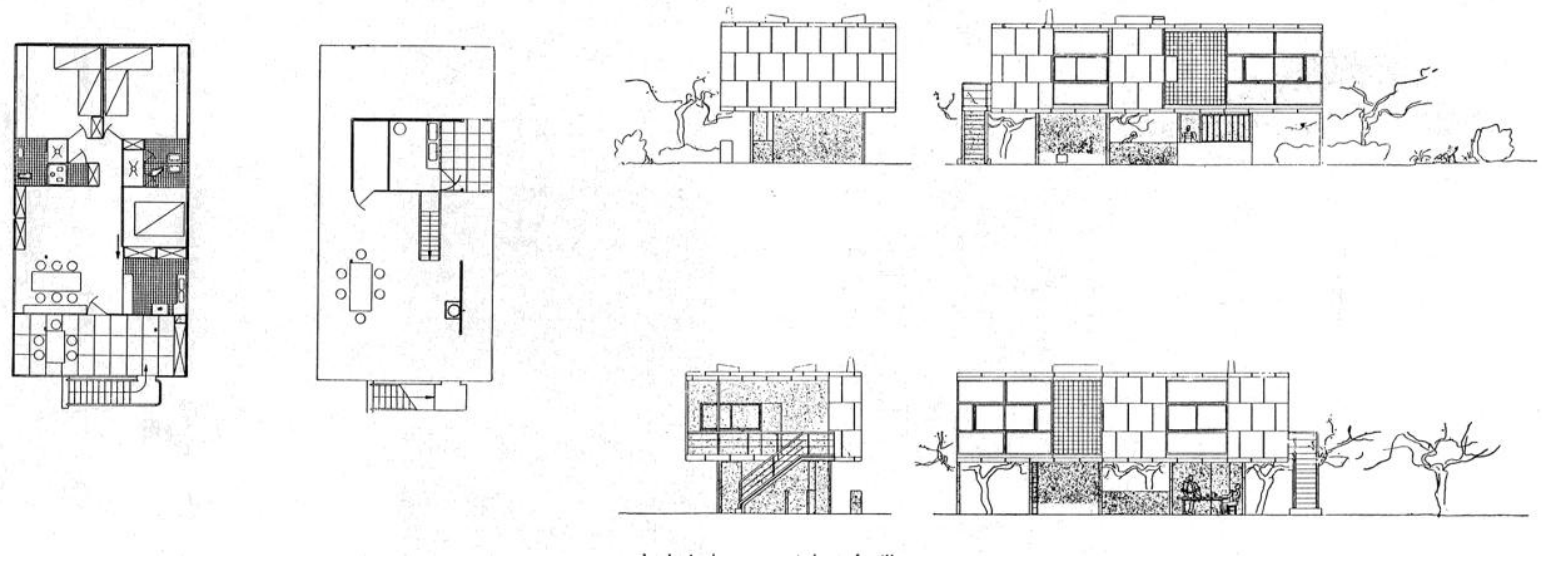

2. Planimetría de la vivienda, Ferme Radieuse, Le Corbusier: Euvre Complète 1929-1934. Zurich: Girsberger, 1935. p. 187.

\footnotetext{
${ }^{35}$ Le Corbusier: "Réorganisation Rurale”. op. cit. p. 325.
} 
Este proyecto no supuso el diseño de nuevo modelo de vivienda desde cero, sino que fue una reutilización de sus Maisons Loucheur ${ }^{36}$. Proyecto que se planteó en el marco de la ley Loucher ${ }^{37}$ para la construcción masiva de vivienda barata a finales de la década de los 20 . Por tanto debía ser una construcción económica, prefabricada y de rápido montaje que además siguiera las tendencias del momento respecto a la vivienda mínima. A diferencia de las Maisons Loucheur, la casa para la Ferme Radieuse no era pareada, eliminando el muro medianero de piedra, convirtiéndose en una vivienda independiente y, si cabe, más técnica, al estar construida en su totalidad en seco con elementos prefabricados.

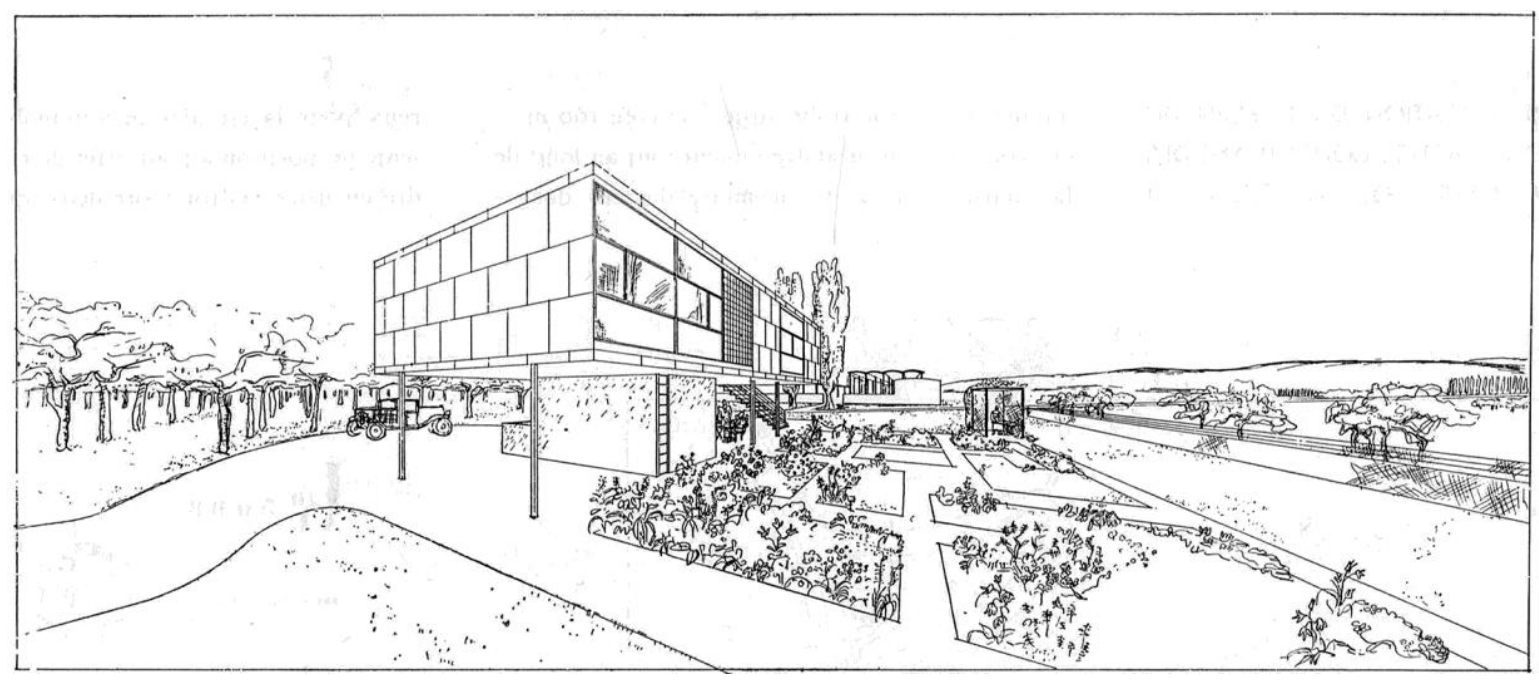

3. Exterior de la vivienda, Ferme Radieuse, Le Corbusier: Euvre Complète 1929-1934. Zurich: Girsberger, 1935. p. 191.

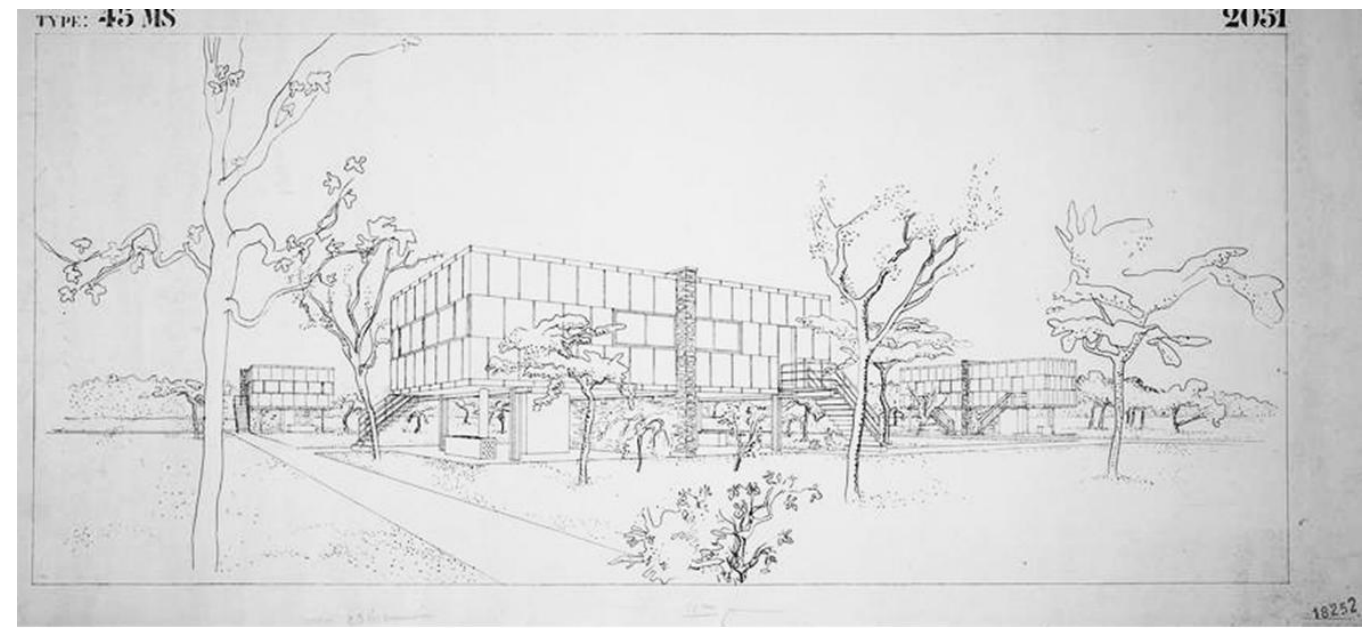

4. Vista exterior del proyecto de las Maisons Loucheur. FLC 18252.

Al fondo del camino central se ubica el patio de trabajo. Se organiza como un espacio abierto delimitado por muros exteriores, con suelo hormigonado modelado para que evacuen las aguas y proteja a los trabajadores de la humedad y del barro. En torno al patio se dispone una serie de naves construidas a partir de la suma pórticos de acero en módulos de 6 metros que soportan bóvedas rebajadas prefabricadas de hormigón protegidas con un manto de tierra. Estas naves se organizan en una zona para almacenaje de materiales, otra para el granero y otra

\footnotetext{
${ }^{36}$ Le Corbusier: Euvre Complète 1910-1929. Zurich: Girsberger, 1935. p. 199.

${ }^{37}$ Ver más en Benton, Tim: "La Réponse de Le Corbusier à la Loi Loucheur," en Le Corbusier. Une Encyclopédie, Lucan, Jacques (Ed.). Paris: Éditions du Centre Pompidou - CCI, 1987. p. 237.
} 
para los animales. El movimiento del grano y del alimento para el ganado se produce mediante un sistema mecánico similar al de un ferrocarril a pequeña escala suspendido del techo. Éste tiene como objetivo optimizar las labores de separación, selección y almacenaje del grano, así como el cebado del animal y retirada del estiércol para devolverlo al campo. Desde la zona trasera del granero arranca el camino que permite la entrada directa de los productos agrícolas y la salida del estiércol.

En todo el proyecto se aprecia un interés claro por generar un organismo constituido por circuitos funcionales que conecten las actividades humanas, las de los animales y la naturaleza; un "único organismo con un metabolismo interno coherente" ${ }^{38}$. Un artefacto humano, industrial y tecnológico, cuyo objetivo es optimizar los intercambios energéticos entre el territorio, los animales y las personas, una suerte de funcionalismo biológico que busca la armonía entre todos sus componentes.

Una vez finalizado el diseño y publicado en diversos medios, Le Corbusier buscó su materialización, pero la disolución de su grupo sindicalista no lo facilitó. Pese a ello se esforzó en intentar construirlo desde 1934 hasta 1942, incluso en otros países, como en Italia. Durante sus visitas al país transalpino y sus intentos de entrevistarse con Mussolini, Le Corbusier se interesó por las propuestas de recuperación agrícola en la zona del Agro Pontino. Llegó a afirmar que Sabaudia estaba hecha con gusto y llena de buenas intenciones pero no era sino "una imitación artística de los pueblos bonitos de cualquier sitio"39, a diferencia de su granja radiante que era "una herramienta pura, eficaz, necesaria y suficiente, con una función rigurosa y útil" "40. Por ello, ya desde París, le propuso por carta al Duce que construyera 1400 granjas radiantes en el espacio agrícola recuperado en las Lagunas Pontinas ${ }^{41}$. Estos proyectos, sin embargo, no eran adecuados para ese territorio, de gran extensión, completamente plano y dedicado casi exclusivamente al cereal en explotación extensiva; dinámicas diferentes a las del territorio de bocage en el Sarthe francés. Además, frente al corporativismo fascista con alta intervención del estado ${ }^{42}$, el regionalismo sindical implícito en su proyecto requería de una gestión descentralizada y la implicación de los sindicatos.

\section{Village Radieux}

El trabajo de la granja radiante fue presentado posteriormente a George Monnet, ministro socialista de agricultura, que no lo consideró pero, al menos, permitió mostrarlo en la sección de agricultura del Pavillon des temps nouveaux en la Exposición Internacional de París de $1937^{43}$. Aquí, con el título de Reorganisation Agraire, Le Corbusier mostró con dibujos, maquetas y textos el proyecto de la granja radiante y, también, el de un centro cooperativo ${ }^{44}$. En ellos expuso:

"Reorganización agraria, planeamiento rural para volver a la tierra, no hay urbanización para las ciudades sin desarrollo del campo, la industria aportará el equipamiento.

\footnotetext{
${ }^{38}$ García-Germán, Javier: "De la Ville Verte a la Geoarquitertura”. op. cit. p. 198. (cita recogida en castellano).

${ }^{39}$ Le Corbusier: "Réorganisation Rurale". op. cit. p. 336. (Traducción desde el francés por el autor).

40 Ídem.

${ }^{41}$ McLeod, Mary: "Piacé: Ferme Radieuse and Village Radieux”. op. cit. p. 190.

${ }^{42}$ McLeod, Mary: "Le Ferme Radieuse. Le Village Radieux". op. cit. p. 132.

${ }^{43}$ El Pavillon des temps nouveaux de la Exposición Internacional de Arte y Técnicas en París de 1937 fue diseñado por Le Corbusier.

${ }^{44}$ El proyecto de centro-poblado cooperativo se recoge en Le Corbusier: Cuvre Complète 1934-1938. Zurich: Girsberger, 1939. pp. 104-110.
} 
Es la tierra (el tipo de suelo y las estaciones) la que decide, no la gente. La generalización en la agricultura es una receta para el fracaso: primero deben definirse las regiones.

Debe crearse una municipalidad rural: Granjas familiares trabajan la tierra, el poblado como comunidad de servicios compartidos, una empresa cooperativa.

Proyecto de consolidación del campo para una región claramente definida: La vuelta al campo es posible únicamente a través de granjas familiares apoyadas en recursos colectivos (métodos y equipamiento). "45
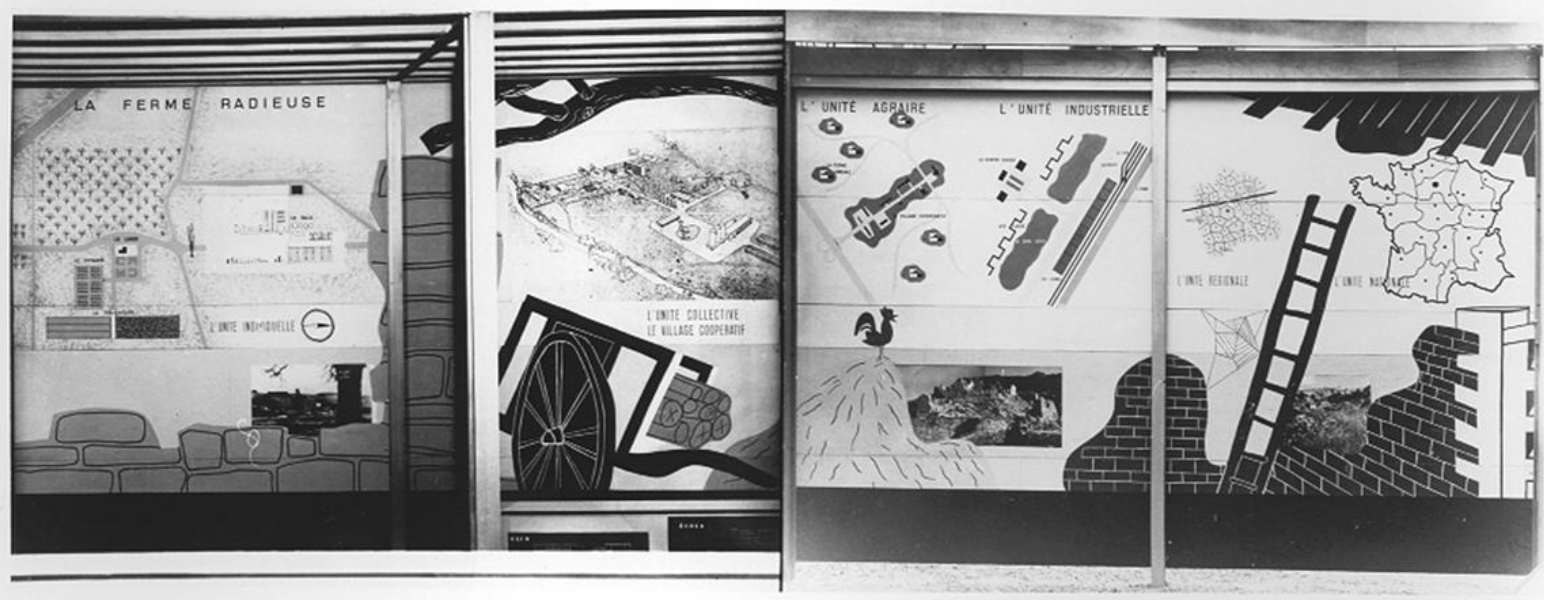

5. Panel sobre la Reforme Agraire en el Pavillon des temps nouveaux en la Exposición de París 1937. FLC L2(13)148.

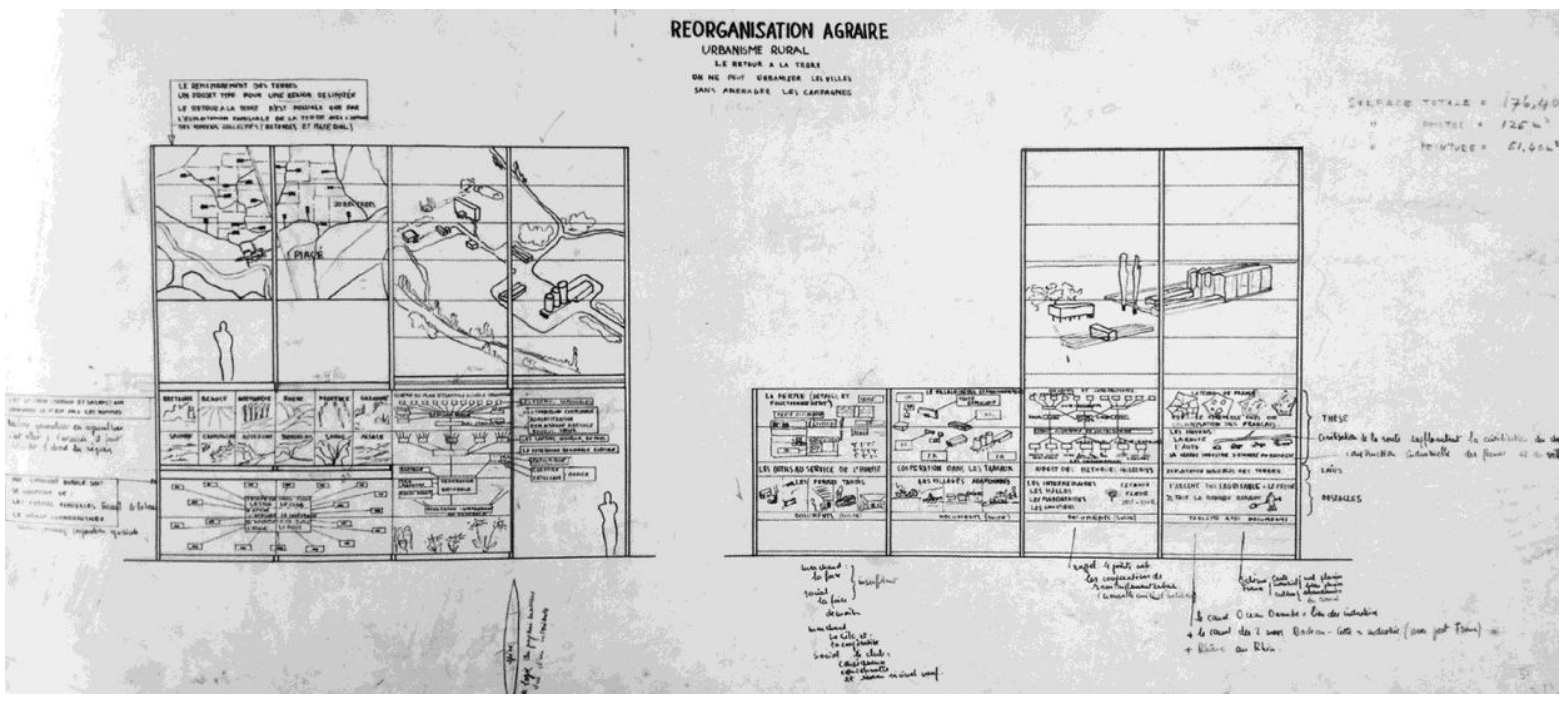

6. Boceto del panel a exponer en el Pavillon des temps nouveaux en la Exposición de París de 1937. FLC 00681.

\footnotetext{
${ }^{45}$ Panel original reproducido en: Cohen, Jean-Louis; Benton, Tim; Tittensor, John (Eds.): Le Corbusier Le Grand. Londres Nueva York: Phaidon, 2014. p. 311. (Traducción desde el francés por autor).
} 


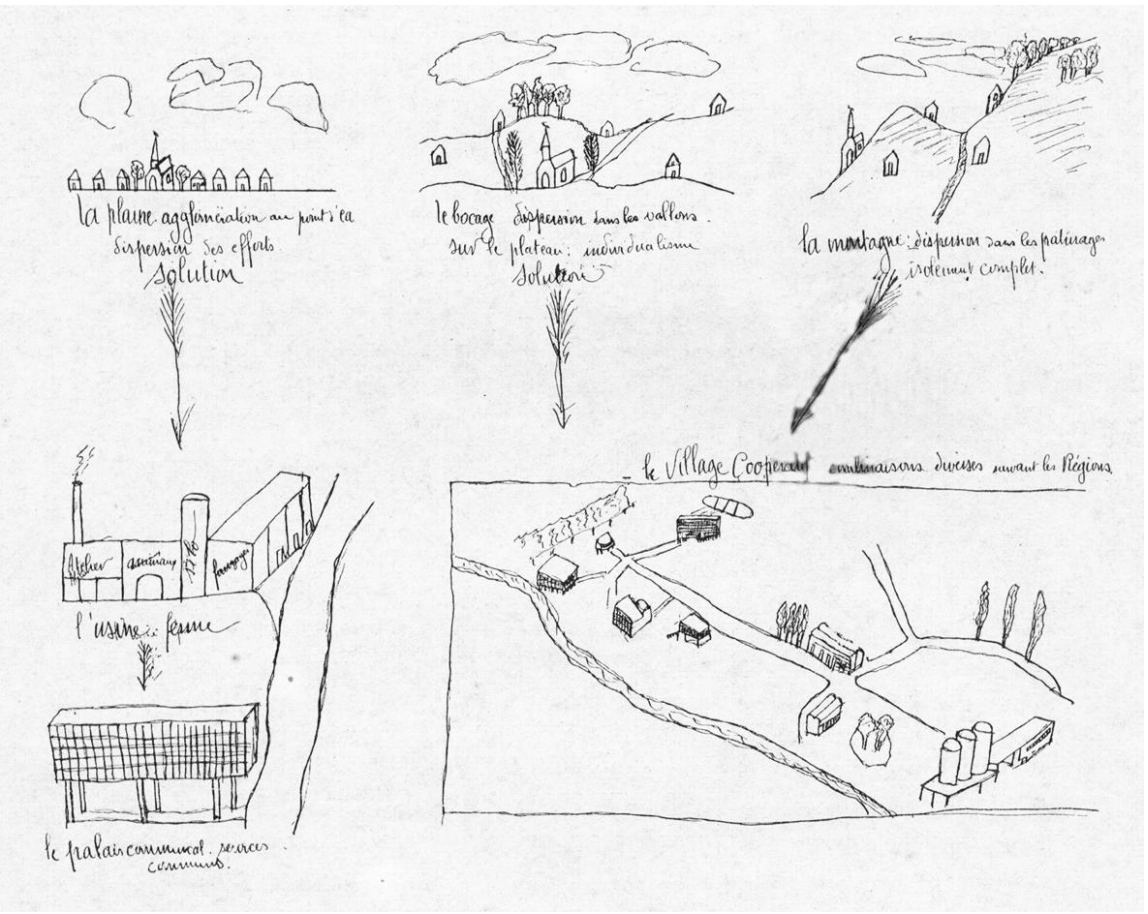

7. Bocetos de Norbert Bézard sobre el territorio de Piacé y el tipo de poblado cooperativo adecuado. En Bézard, Norbert: "Rapport: L’Urbanisme Rural”, En 5 Congrés de Paris 'Logis et Loisirs'. Boulogne-sur-Seine: Editions d'Architecture d'Aujourd'hui, 1938. p. 15.

En esta exposición se mostraba por primera vez una versión elaborada del poblado radiante o centro cooperativo $^{46}$. En las publicaciones anteriores aparecieron esquemas que no pasaban de ser bocetos inspirados en las ideas de Bézard. El diseño definitivo al que llega Le Corbusier en 1937 obviaba la propuesta de emplazarlo sobre una colina que controlara el territorio ${ }^{47}$ y se sitúa en un lugar teóricamente plano y bien comunicado. Partía de una organización similar a la de la granja, por lo que una espina central distribuía el conjunto y conectaba el poblado, no ya con los campos, sino con una vía rodada de alta capacidad. Se percibe, de una manera más clara, el deseo de incorporar a la vida rural, condiciones socioeconómicas comparables a las de las ciudades.

Según este modelo, los propietarios de granjas radiantes se asociarían formando comunas de producción, cuyo centro sería un Village Radieux. Éste se presenta en disposición abierta e integrada en el medio, con funciones que van desde las netamente agrarias, a las de contacto social, pasando por las industriales o las de servicio. Se desarrollarían en un conjunto de construcciones dispersas en un entorno verde, materializadas por medio de estructuras prefabricadas de acero y cubiertas con bóvedas rebajadas de hormigón. Los interiores y los remates no serían prefabricados, sino que se harían por obreros locales usando técnicas de la zona.

La organización de las funciones comienzan, desde el acceso, por las agrarias. El silo cooperativo, el "vientre"48 del proyecto, funciona como marca de la comunidad en el territorio. Su importancia radica tanto en su función real, recipiente de almacenaje y centro de gestión de la producción, como en su dimensión simbólica, elemento de gran potencia en el paisaje que transmite a los campesinos la seguridad de que sus cosechas están protegidas y a salvo de la especulación. Tras este primer conjunto aparece una serie de instalaciones para las actividades industriales, en donde se producirían piezas para la gran industria y se transformarían in situ los productos

${ }^{46} \mathrm{Al}$ año siguiente apareció el proyecto reflejado en Le Corbusier: "La Réforme Agraire, Le Village Radieux," en Des Canons, Des Munitions? Merci! Des Logis... SVP. Boulogne-sur-Seine: Editions d'Architecture d'Aujourd'hui, 1938. pp. 114-137.

${ }^{47}$ McLeod, Mary: "Piacé: Ferme Radieuse and Village Radieux”. op. cit. p. 189.

${ }^{48}$ Le Corbusier: El Urbanismo de los tres establecimientos humanos. op. cit. p. 80. 
cosechados, evitando la desaparición de las artesanías populares. Junto a ello se emplaza el almacén de distribución y venta de productos agropecuarios, además de la cooperativa de abastecimiento, que permitiría el acceso a productos que habitualmente no pasaban de los centros de más demanda.

Avanzando por el eje central aparecen equipamientos de servicios (correo postal), residenciales (bloque de viviendas en régimen de alquiler con usos comunitarios), educativos (escuela) y de ocio (club). El club, de clara influencia soviética y denominado por Le Corbusier la "cabeza" del poblado, funcionaría como el principal punto de encuentro comunitario. El esquema quedaría presidido por el edificio administrativo, sede del ayuntamiento y del sindicato, al fondo de la vía central.

Los servicios ofrecidos y la conectividad regional permitida, hacían que Le Corbusier entendiera el poblado como un "dispositivo técnico portador de seguridad y esperanza en el mundo campesino" 49 , permitiendo a la comunidad dar el salto desde su universo inmediato y conocido de los $4 \mathrm{~km} / \mathrm{h}$, al abierto y desconocido de los 50 $100 \mathrm{~km} / \mathrm{h}^{50}$. Resolviendo en su conjunto los tres problemas básicos planteados de inicio, los de "circulación, almacenamiento y manipulación" ${ }^{\prime 51}$. Además, materializaba otra de sus inquietudes, la armonía entre el individuo y el colectivo, entre la célula y el organismo. Y es que, junto con las ideas centrales de reorganización del suelo, el modelo cooperativo aseguraba esta armonía por medio de unos usos (club, escuela, talleres, oficinas) considerados como extensiones del hábitat, inseparables de cualquier proyecto residencial, tanto en la ciudad como en el campo.

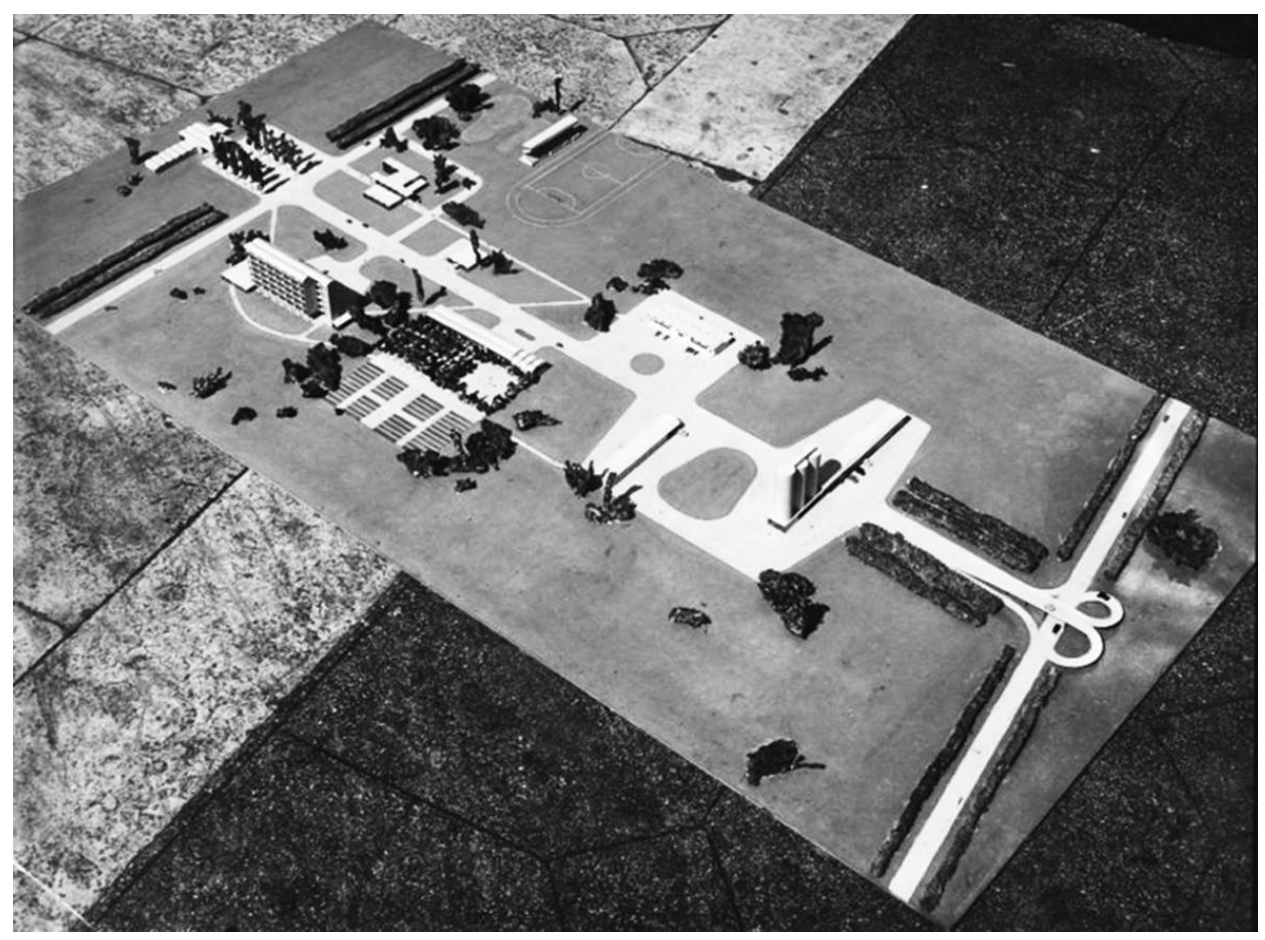

8. Fotografía de la maqueta del Village Radieux. FLC L3(20)61.

La exposición de la reforma agraria en el pabellón de 1937 permitió a Le Corbusier contar con un material de gran calidad para seguir mostrando su proyecto, y así lo hizo inmediatamente en el V congreso del CIAM. Este fue probablemente el foro que aportó mayor repercusión a la propuesta, al darse a conocer a los más relevantes

\footnotetext{
49 Ídem.

${ }^{50}$ Ibíd., p. 74.

${ }^{51}$ Le Corbusier: "Réorganisation Rurale". op. cit. p. 327.
} 
arquitectos del momento. Sin embargo, recibió la crítica, entre otros, de los arquitectos holandeses cercanos al socialismo. Estos atacaron fuertemente la idea de regionalismo y el modelo de agricultura de pequeña escala en la que los agricultores mantenían la propiedad, opuesto a sistema intervencionista y extensivo que defendían ${ }^{52}$.

La poca aceptación en el Congreso de París no fue óbice para que Le Corbusier continuara madurando estas ideas; así lo reflejan las referencias que hizo a ellas en 1939 tanto en la revista Sillons ${ }^{53}$ como en el manuscrito Sur les 4 Routes $^{54}$; o los comentarios que incluyó en la Maison des Hommes ${ }^{55}$. En 1940 elaboró otro manuscrito que firmó junto a Bézard titulado La Ferme radieuse et le Centre Coopératif. Reorganisation Agraire. Programme de la grande industrie ${ }^{56}$, donde cambió el nombre de "village" por "centre" y "radieux" por "coopératif", enfatizando así en el modelo de gestión. Posteriormente, Le Corbusier intentó trasladar estos proyectos al Gobierno de Vichy e incluso se han recogido propuestas de implantación en los Estados Unidos ${ }^{57}$, que llegaron a tener impacto en las políticas de construcción de vivienda social en el oeste del país, especialmente por medio de la oficina de San Francisco de la Farm Security Administration ${ }^{58}$.

\section{Unité d'explotation agricole}

La fundación en 1942 del grupo ASCORAL permitió a Le Corbusier contar con un equipo para afrontar esquemas organizativos a escala territorial. Aujame, Hanning, Dubreuil o el propio Bézard colaboraron en las investigaciones que se recogieron en la publicación de 1945 Les Trois Établissements Humains ${ }^{59}$. Los Tres Establecimientos Humanos puede considerarse su última gran propuesta urbanística a escala territorial, la cual defenderá hasta el final de su vida.

La unidad de explotación agrícola, junto con la ciudad lineal industrial y la ciudad radiocéntrica de intercambios, conformarían la tríada de asentamientos funcionales que constituyen el modelo territorial propuesto. Se trataba, por tanto, de un nivel más en su trabajo sobre la reorganización del hábitat rural, pasando del diseño de unos modelos de granja y de poblado cooperativo a su implementación en una teoría completa de ordenación del territorio.

En este modelo, la superficie delimitada por la red de ciudades industriales lineales se colmataría por medio de una malla de explotaciones de planta poligonal, maximizando la utilización productiva de los recursos naturales. Estructura territorial de enorme similitud con la propuesta de Walter Christaller ${ }^{60}$ en 1933 para el territorio agrícola del sur de Alemania, sobre la que Le Corbusier podría haber tenido conocimiento en algún momento ${ }^{61}$. En el diseño de cada explotación agrícola poligonal, Le Corbusier pasa del modelo aislado que mostró en la década anterior a una mayor concreción espacial. A partir de la existencia de una serie de aldeas, procede a la

${ }^{52}$ CIAM: 5 Congrés de Paris "Logis et Loisirs". Boulogne-sur-Seine: Editions d'Architecture d'Aujourd'hui, 1938. pp. 1078 .

${ }^{53}$ Le Corbusier: "Renaissance de la Vie Paysanne". Sillons. 1939, № 1.

${ }^{54}$ Se publicó dos años después en Le Corbusier: Sur les 4 Routes. París: Éditions Gallimard, 1941.

${ }^{55}$ Le Corbusier; de Pierrefeu, François: Maison des Hommes. París: Éditions Plon, 1942. p. 121.

${ }^{56}$ Manuscrito recientemente publicado en Francia: Le Corbusier; Bézard, Norbert: La ferme radieuse et le centre coopératif., Benoît Hérisson (Ed.). Piacé: Piacé le radieux, 2015.

${ }^{57}$ Bacon, Mardges: Le Corbusier in America: Travels in the Land of the Timid. Cambridge, Mass.: MIT Press, 2001. p. 288.

${ }^{58}$ Ver los proyectos Rural Community en Woodville y Agricultural Workers' Community en Chandler recogidos en: Mock, Elizabeth: Built in USA: A Survey of Contemporary American Architecture. Nueva York: MoMA, 1945.

${ }^{59}$ Le Corbusier: Les Trois Établissements Humains. op. cit.

${ }^{60}$ Christaller, Walter: Die zentralen Orte in Süddeutschland (1933). Darmstadt: Wissenschaftliche Buchgesellschaft, 1968.

${ }^{61}$ Frampton, Kenneth: Le Corbusier. Madrid: Ediciones Akal, 2001. p. 111. 
ordenación funcionalista del territorio. En una posición central, y cercana a la vía de comunicación nacional o regional que atraviese la zona, se ubica el poblado cooperativo. En el espacio inmediatamente anexo a él, se sitúan los cultivos intensivos de hortalizas y frutales para consumo local o venta. En un segundo anillo se desarrollan los cultivos extensivos de cereales, tubérculos y viñas, entre los cuales se reservan espacios para la cría de la ganadería. Dispersas por este segundo anillo se disponen las granjas radiantes.

Las vías ya existentes se refuerzan y, junto con otras de nueva construcción, permiten la conectividad entre los poblados, el centro cooperativo, las granjas y los espacios de cultivo. El proyecto incluye la definición pormenorizada del poblado cooperativo, repitiendo el modelo de 1937 con leves modificaciones en cuanto a la ubicación del club, y la ordenación de la granja radiante, sin cambios respecto a la original.
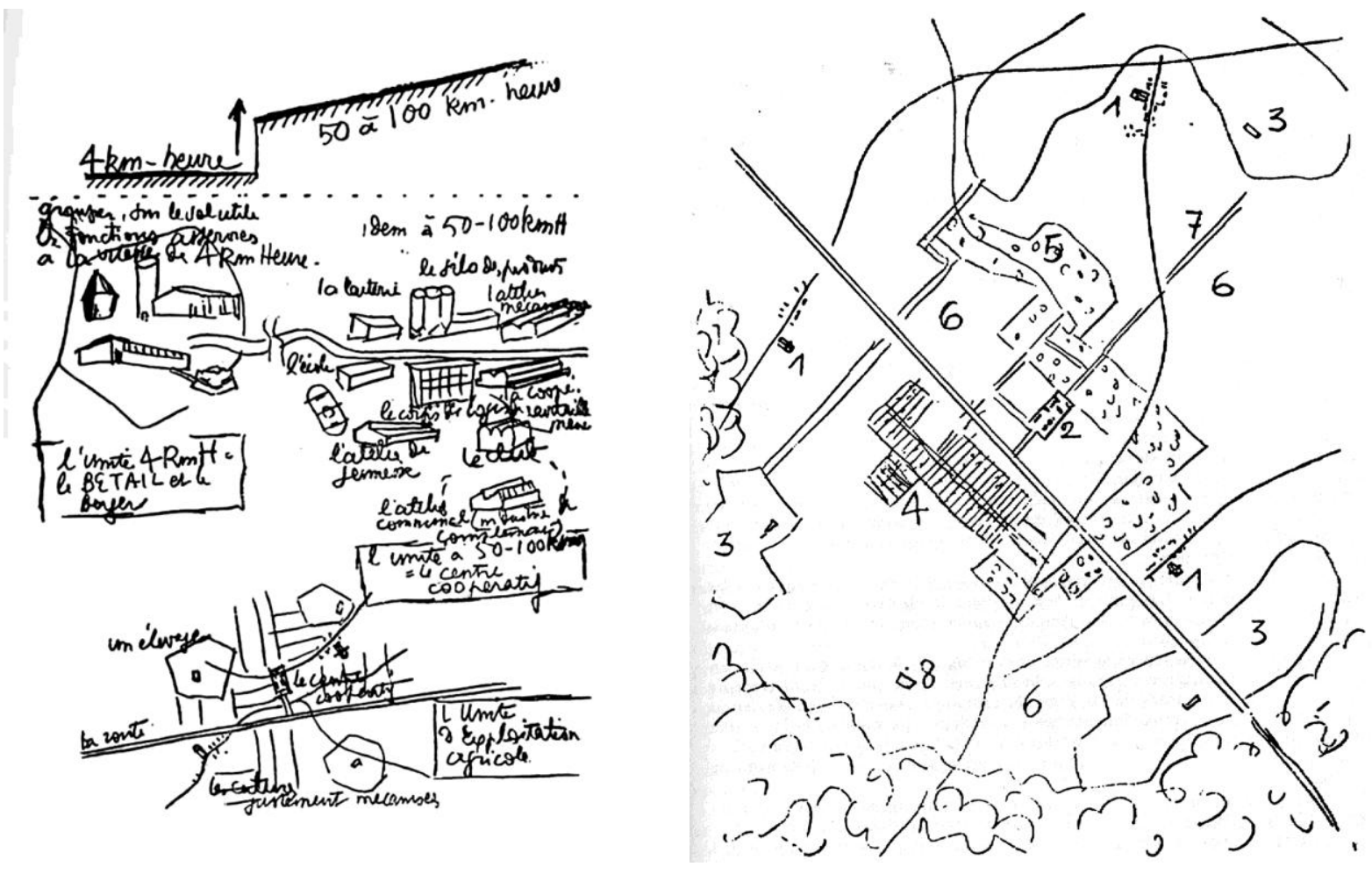

9 y 10. Esquemas sobre Les Trois Établissements Humains, y la Unité d'Explotation Agricole, en Le Corbusier: L' urbanisme des Trois Établissements Humains. París: Ed. de Minuit, 1959. p. 75 y p. 77.

La modernización de la organización propuesta no sólo beneficiaría al funcionamiento de la tierra, sino que permitiría incluso la promoción de industrias específicas, tales como manufacturas y enlatados de verduras y frutas, producción de leche y derivados, industria maderera, caza, etc. Una industria que podría llegar a ser "brillante y optimista, plena de intensidad y belleza"62 gracias a su conexión con el resto de asentamientos humanos. Las ciudades industriales lineales mejorarían y protegerían el campo ya que aseguraban que la industria se desarrollara en lugares concretos y no invadiera el territorio de manera incontrolada. Además, permitían a las zonas agrícolas conectarse con los flujos económicos y culturales, dignificando e intensificando el campo sin perder su esencia agraria. Para Le Corbusier, éste era algo más que un modelo territorial, era la solución a la sociabilidad humana, la única manera de establecer una ocupación "conforme" del territorio ${ }^{63}$ frente a la progresiva desnaturalización de la vida humana.

\footnotetext{
${ }^{62}$ Dubois, Gilles: "Le Corbusier, L'agriculture et L'urbanisme”. op. cit. (Traducción desde el francés por el autor).

${ }^{63}$ Torres Cueco, Jorge: Pensar la Arquitectura (...).op. cit. p. 98.
} 
Pese al convencimiento del maestro suizo, ningún gobierno puso en marcha su modelo territorial. Ya después de la Segunda Guerra Mundial, en el año 1956, propuso la idea a un antiguo miembro de la revista Prèludes, Philippe Lamour, encargado del desarrollo de la zona del Bajo Ródano-Languedoc ${ }^{64}$. Al igual que pasara en Italia, las diferencias del territorio con respecto al que se había utilizado como modelo de estudio, hicieron inviable su implementación. Pero la idea siguió en la mente de Le Corbusier hasta el final. Como ya se ha comentado, en su última obra teórica Mise au Point, este modelo de reorganización territorial ocupó una parte importante de su discurso, lo que demuestra la continuidad en el pensamiento de Le Corbusier, que nunca dio etapas por cerradas sino que trabajó cribando y perfeccionando sus proyectos hasta el extremo.

\section{Conclusiones}

La granja y el poblado radiantes surgieron como soluciones al problema de una sociedad rural aislada. El progreso industrial había provocado una tremenda desconexión entre lo urbano y lo rural, que se encontraban en mundos diferentes. Frente a ello, la unidad de explotación agrícola, junto con los otros modelos de asentamiento humano, intentaría maximizar la productividad y facilitar la conectividad, lo que reduciría los desequilibrios territoriales existentes.

El diseño concreto de las explotaciones agrícolas se realiza entendiéndolas como asentamientos humanos de primer nivel, en los que se llevan a cabo actividades que deben tener condiciones y servicios de calidad, similares a los que se disfrutan en el medio urbano. Además de su comunicación con las redes territoriales, se les dota de servicios comunitarios que fomenten el encuentro y el intercambio, y se utilizan materiales, técnicas y estándares de confort contemporáneos. En definitiva, se busca conseguir condiciones óptimas de comodidad en la residencia, de eficiencia y productividad en el trabajo y una interesante oferta de ocio y cultura que rompan la marginación del mundo rural.

La novedad de la propuesta lecorbusierana es, por tanto, el diseño de una conectividad funcional. Pese a su independencia física, el funcionamiento de los asentamientos depende de los flujos de encuentro y retroalimentación; del intercambio de productos, servicios y suministros que se producirían en los puntos de contacto. Esta visión contemporánea, está posibilitada por las novedades técnicas procedentes del mundo de los transportes y de la construcción. Utilizándose conceptos urbanísticos como el zoning o la conectividad entre redes, y arquitectónicos, como la construcción modular, el uso de estructuras porticadas, la disposición elevada de las viviendas sobre pilotis, la abstracción volumétrica de las piezas, etc.

Por otro lado, también es novedosa la propuesta cooperativista. Un modelo de reforma agraria no basada en una apropiación estatal de la tierra si no en la constitución de cooperativas de propietarios-trabajadores agrícolas que servirían de intermediarias para la gestión comunitaria de sus recursos y productos. Frente al individualismo antiurbano imperante en propuestas teóricas como la de Wright, o el intervencionismo estatal soviético de la propuesta de Ginzburg, en la de Le Corbusier prima una adecuada combinación entre individuo y sociedad. Un modelo que mantiene la independencia de la propiedad pero colectiviza aquellos elementos que cada agricultor individualmente no podría conseguir, tanto materiales como inmateriales.

\footnotetext{
${ }^{64}$ McLeod, Mary: “Piacé: Ferme Radieuse and Village Radieux”. op. cit. p. 191.
} 
De manera que Le Corbusier no cae en estos proyectos en un "romanticismo campesino", sino que mantiene una mirada universal, moderna y funcional que conseguiría la integridad biológica del ser humano. Actitud que, por otro lado, demuestra una distancia teórica con respecto al problema real. Le Corbusier siempre defendió que la granja era como un tractor o una cosechadora por lo que debía "ser complementada con la experiencia de un campesino, sin cuya sabiduría resultaría fallida su integración en el metabolismo de la granja y en la ecología del lugar" 65 . Por lo que es claro que no se concibió como una solución de aplicación literal, sino como un modelo o prototipo que debería adaptarse a las diferentes zonas y saberes populares. Sin embargo, la realidad es que en tres décadas nunca adaptó ni modificó el proyecto, paso que probablemente hubiera dado en el caso de su construcción.

Este inmovilismo demuestra que la perspectiva desde la que se enfocó el problema fue técnica, científica y urbana. Tanto la granja, como el poblado y la unidad de explotación agrícola se diseñaron estableciendo ejes de organización, creando anillos según usos, generando distribuciones homogéneas, etc. Lo cual podría entenderse como la implementación de una visión tecnicista, en lugar de una renovación alcanzada a través de las reclamaciones de los usuarios reales. Una ordenación mecánica, propia de la época, sobre un medio que probablemente debiera haber sido entendido en su mayor complejidad, teniendo en cuenta las singularidades y ritmos del mundo agrario.

Si situamos el proyecto de Le Corbusier en su contexto, entendemos que entronca con las propuestas de Taut, Wright, Hilberseimer o Ginzburg relatadas al inicio del artículo. Plantearon un enfoque global hasta entonces nunca realizado: el diseño de modelos agrarios perfectamente conectados con el resto de los sectores económicos, materializados con una arquitectura contemporánea. Demostraron un enorme interés por mejorar las condiciones de los agricultores, grupo social que aún no se había sumado a la modernidad, mediante la incorporación de la tecnología, la mejora de la habitabilidad y la inclusión social, sin perder las bondades del contacto con la naturaleza y con la producción de alimentos. Un conjunto de propuestas de enorme valor que representan la manera de entender la planificación del territorio en esta década de los 30, tan necesitada de renovación. Miradas urbanas, funcionales y técnicas que para su materialización hubieran necesitado de cambios profundos que superaban las posibilidades del planeamiento.

\section{Bibliografía}

Arredondo Garrido, David: “Agricultura en la ciudad. De la Utopía a la Conciencia de Lugar”. Directores: Juan Calatrava Escobar y Juan Manuel Barrios Rozúa. Universidad de Granada, 2013.

Bacon, Mardges: Le Corbusier in America: Travels in the Land of the Timid. Cambridge, Mass.: MIT Press, 2001.

Benton, Tim: "La Réponse de Le Corbusier à la Loi Loucheur" en Le Corbusier. Une Encyclopédie, Lucan, Jacques (Ed.). Paris: Éditions du Centre Pompidou - CCI, 1987. p. 237.

Bézard, Norbert: “Rapport: L’Urbanisme Rural”. En 5 Congrés de Paris 'Logis et Loisirs'. Boulogne-sur-Seine: Editions d'Architecture d'Aujourd'hui, 1938. pp. 3-16.

Christaller, Walter: Die zentralen Orte in Süddeutschland. Darmstadt: Wissenschaftliche Buchgesellschaft, 1968.

Congreso Internacional de Arquitectura Moderna (CIAM): 5 Congrés de Paris 'Logis et Loisirs'. Boulogne-surSeine: Editions d'Architecture d'Aujourd'hui, 1938.

\footnotetext{
${ }^{65}$ García-Germán, Javier: "De la Ville Verte a la Geoarquitertura”. op. cit. p. 205.
} 
Cohen, Jean-Louis; Benton, Tim; Tittensor, John (Eds.): Le Corbusier Le Grand. Londres - Nueva York: Phaidon, 2014.

Dubois, Jacques: “Le Corbusier, L'agriculture et L'urbanisme”. Habitation: Revue Trimestrielle de La Section Romande de l'Association Suisse Pour l'Habitat. 1957, No 29.

Frampton, Kenneth: Le Corbusier. Madrid: Ediciones Akal, 2001.

García-Germán, Javier: "De la Ville Verte a la Geoarquitertura”. Massilia. Annuaire d'Etudes Corbuseennes. 2008, No 7. pp. 196-209.

Ginzburg, Moisei; Barshch, Mikhail: “Zelenyj Gorod.” SA Sovremennaya Arkhitektura. 1930, No 1-2. p. 22.

Hilberseimer, Ludwig: The New Regional Pattern; Industries and Gardens, Workshops and Farms. Chicago: P. Theobald, 1949.

Hilpert, Thilo: "La Maison des Hommes: Leçons Possibles de L'anthropocentrisme de Le Corbusier." en Le Corbusier et La Nature. Paris: Fondation Le Corbusier - Editions de la Villette, 2004. pp. 21-32.

Le Corbusier: "Décisions". Plans. Diciembre 1931, №10.

—. El Urbanismo de los tres establecimientos humanos. Junyent, Albert (Tr). Barcelona: Poseidón, 1981.

_. "Ferme Radieuse, Village Radieux". Prélude. 1934, Nº 14.

_. La Ville Radieuse. Boulogne-sur-Seine: Editions d'Architecture d'Aujourd'hui, 1935.

. "La Réforme Agraire, Le Village Radieux" en Des Canons, Des Munitions? Merci! Des Logis... SVP. Boulogne-sur-Seine: Editions d'Architecture d'Aujourd'hui, 1938. pp. 114-37.

—. Les Trois Établissements Humains. Paris: Éditions Denoël, Collection ASCORAL, 1945.

—. Logis et Loisirs. Boulogne-sur-Seine: Editions d'Architecture d'Aujourd'hui, 1938.

—. L' Urbanisme des Trois Établissements Humains. Paris: Ed. de Minuit, 1959.

—. Mise au point. Torres Cueco, Jorge (Ed.). Madrid: Abada Editores, 2014.

_. Euvre Complète 1910-1929. Zurich: Girsberger, 1935.

_. Euvre Complète 1929-1934. Zurich: Girsberger, 1935.

_. Euvre Complète 1934-1938. Zurich: Girsberger, 1939.

_. "Renaissance de la Vie Paysanne." Sillons. 1939, № 1.

_. "Réorganisation Rurale” en La Ville Radieuse, Paris: Vincent Fréal and Cie., 1964. pp. 319-36.

- Sur les 4 Routes. París: Éditions Gallimard, 1941.

- The City of To-Morrow and Its Planning. New York: Dover, 1987.

_.. "Village Radieux, Ferme Radieuse”. L'Homme Réel. 1934, № 4. pp. 54-59.

Le Corbusier; Bézard, Norbert: La Ferme Radieuse et le Centre Coopératif. Hérisson, Benoît (Ed.). Piacé: Piacé le radieux, 2015.

Le Corbusier; de Pierrefeu, François: Maison des Hommes. París: Éditions Plon, 1942.

Lourau, René: El Estado y el inconsciente: ensayo de sociología política. Barcelona: Kairós, 1980.

McLeod, Mary: "Le Ferme Radieuse. Le Village Radieux” en Le Corbusier et La Nature. Paris: Fondation Le Corbusier - Editions de la Villette, 2004. pp. 129-50.

- "Piacé: Ferme Radieuse and Village Radieux" en Le Corbusier: An Atlas of Modern Landscapes, Cohen, Jean-Louis (Ed.). New York: Museum of Modern Art, 2013. pp. 185-92. 
—. "Radiant Farm and Village: Le Corbusier's Agricultural Utopia, 1933-1942." Dumbarton Oaks, Washington: Dumbarton Oaks Garden and Landscape Studies, 2012.

"Urbanism and Utopia: Le Corbusier from Regional Syndicalism to Vichy.” Princeton University, 1985

Mock, Elizabeth: Built in USA: A Survey of Contemporary American Architecture. Nueva York: MoMA, 1945.

Ragot, Gilles: "La Ferme et le Village radieux de Le Corbusier. Nouvelle déclinaison du principe d'équilibre entre l'individuel et le collectif'. In Situ. Revue des patrimoines. Julio 2013, No 12.

Taut, Bruno. Die Auflösung der Städte. Die Erde eine gute Wohnung, der Weg zur alpinen Architektur. Hagen: Folkwang, 1920.

. Escritos, 1919-1920. Iñaki Ábalos (Ed.). Madrid: Croquis, 1997.

Torres Cueco, Jorge: Pensar la Arquitectura: 'Mise au point' de Le Corbusier. Madrid: Abada Editores, 2014.

Waldheim, Charles: "Notes Toward a History of Agrarian Urbanism." en Bracket 1: On Farming, White, Mason; Przybylski, Maya (Eds.). Barcelona: Actar, 2010. pp. 18-24.

Wright, Frank Lloyd. The Disappearing City. New York: W. F. Payson, 1932.

. The Living City. New York: Horizon Press, 1958.

When Democracy Builds. Chicago: University of Chicago Press, 1945. 